\title{
FORMAÇÃO DE PROFESSORES NO CONTEXTO NEOLIBERAL
}

\author{
Júlia Cecília de Oliveira Alves Ribeiro ${ }^{1}$, Cláudio Pinto Nunes ${ }^{2}$
}

${ }^{1}$ Mestranda em Educação pela Universidade Estadual do Sudoeste da Bahia - PPGED/UESB. Docente da rede pública municipal de Dário Meira - BA. E-mail: juliaailicec@hotmail.com

${ }^{2}$ Doutor em Educação pela Universidade Federal do Rio Grande do Norte - UFRN. Docente da Universidade Estadual do Sudoeste da Bahia - UESB. E-mail: claudionunesba@hotmail.com

\section{RESUMO}

Este artigo visa discutir a formação docente, que passou por inúmeras transformações nas duas últimas décadas. Algumas delas representam avanços em termos de legislação e garantia de direitos referente à formação, outras porém representam enormes retrocessos, influenciadas pelas tendências neoliberais e pela interferência dos reformadores educacionais que tem conseguido apoio do Estado para atingir suas metas de reprodução da sociedade e formação de mão de obra para o mercado de trabalho. Neste contexto, apresentamos a necessidade da atuação política dos docentes para garantir o cumprimento das leis que amparam seus direitos e o enfrentamento às ações que tem impedido sua valorização. Tal discussão está ancorada em uma análise documental e na pesquisa bibliográfica de obras de autores, como Saviani (2003), Mészáros (2001), Martins (2010) e Freitas (2014), que utilizam os pressupostos do materialismo histórico e dialético em suas pesquisas.

Palavras-chave: Formação de Professores. Neoliberalismo. Reformadores Educacionais. Formação Política

\section{TRAINING OF TEACHERS IN THE NEOLIBERAL CONTEXT}

\section{ABSTRACT}

This article aims to discuss teacher education, which has undergone numerous transformations in the last two decades. Some of these represent advances in terms of legislation and guarantee of rights in education, but others represent enormous setbacks, influenced by neoliberal tendencies and the interference of educational reformers who have been able to gain state support to achieve their goals of society reproduction and hand training for the labor market. In this context, we present the need for the political action of teachers to ensure compliance with the laws that protect their rights and facing the actions that have prevented their appreciation. This discussion is anchored in a documentary analysis and in the bibliographical research of works by authors such as Saviani (2003), Mészáros (2001), Martins (2010) and Freitas (2014), who use the assumptions of historical and dialectical materialism in their research Keywords: Teacher education. Neoliberalism. Educational Reformers. Political Formation

\section{INTRODUÇÃO}

A formação docente no Brasil sofreu inúmeras transformações ao longo das últimas décadas, tanto no âmbito da legislação, como na oferta e na própria concepção de formação de professores. Devemos, portanto, levar em conta que tais transformações na formação geram mudanças ainda maiores na educação como um todo e que estas não podem ser analisadas fora do contexto sócio-político-econômico em que acontecem. Lombardi (2010) reforça esta ideia, ao afirmar que a educação deve ser pensada historicamente, de forma a acompanhar o próprio processo de transformação das relações fundamentais do modo de produção vigente, qual seja, o modo capitalista. O fato de estarmos tratando de um período neoliberal, marcado pelo domínio do capital e pela inserção cada vez mais forte do setor privado na esfera pública, nos obriga a analisar as mudanças em questão de modo minucioso, a fim de encontrarmos a essência das mesmas.

Embora a legislação a respeito da formação docente tenha avançado muito, 
principalmente nas duas últimas décadas, é possível perceber por meio de dados do Instituto Nacional de Estudos e Pesquisas Educacionais Anísio Teixeira - INEP (BRASIL, 2018), que muitas dessas leis, a exemplo do PNE, não estão sendo cumpridas integralmente, ou não estão atingindo os objetivos para os quais foram criadas. A situação da educação brasileira demonstra que carecemos de uma sólida formação de professores, que, diferente do esvaziamento de sua função, como se tem visto, contribua para uma sólida formação também dos educandos.

Por meio deste artigo, pretendemos analisar a formação de professores, levando em consideração as conquistas desta categoria no que se refere aos direitos que lhe foram assegurados pela lei, bem como as estratégias que estas mesmas leis abarcam de prevalência dos interesses neoliberais, e a partir desta contradição, estabelecer uma relação entre a necessária formação política de tais profissionais e o enfrentamento à tentativa de transformar o trabalho docente num trabalho alienado.

Saviani (1984) considera a educação como fenômeno próprio dos seres humanos e, ao mesmo tempo, uma exigência de e para o processo de trabalho, entendendo o trabalho como atividade que promove a humanização e emancipação e não como instrumento que sirva exclusivamente para manter a dominação de uma classe social sobre outra. Partindo dessa premissa, tentaremos desenvolver uma reflexão sobre a atual situação da formação de professores no Brasil no contexto neoliberal e as possibilidades de mudança e avanços neste quesito da valorização docente.

Para tanto, lançaremos mão de uma análise documental de leis que se referem à formação e à valorização docente, pois, segundo Gil (2002, p. 46), estas fontes apresentam "papel importante, tendo em vista que os documentos reúnem fonte rica e estável de dados e que subsistem ao longo do tempo" e de uma pesquisa bibliográfica, que, segundo Lakatos e Marconi (2003, p. 183), tem a intenção de "colocar o pesquisador em contato direto com tudo o que foi escrito, dito ou filmado sobre determinado assunto". Tal pesquisa foi norteada pelos pressupostos do materialismo histórico dialético, que nos permitem interpretar a realidade como resultado, não do mero acaso, mas de um movimento histórico de contradições e correlações de forças que a determinam (FERREIRA JR, 2017). Salientamos que este método, também adotado por autores citados neste trabalho, nos impulsiona a procurar alternativas para a situação educacional vivenciada no Brasil, através da ação crítica e consciente dos profissionais docentes, principais sujeitos da pesquisa em questão.

\section{A FORMAÇÃO DE PROFESSORES NA LEGISLAÇÃO}

A formação inicial e continuada de professores no Brasil passou por muitas transformações através de leis e resoluções a partir dos anos 2000. Embora os debates acerca deste tema tenham se intensificado nas décadas de 1980 e 1990, culminando em avanços para a categoria já a partir da Constituição Federal e da promulgação da Lei de Diretrizes e Bases da Educação de 1996, focaremos nossa atenção no início do século XXI aos dias atuais, dados os recortes do presente trabalho.

O primeiro documento oficial do período em questão é o parecer CNE/CP 9/2001 que apresenta as Diretrizes Curriculares Nacionais para a Formação de Professores da Educação Básica, em nível superior, curso de licenciatura, de graduação plena. Este parecer menciona os enormes desafios educacionais enfrentados nas últimas décadas do século XX (80 e 90), os quais motivaram a mobilização da sociedade, a realização de estudos e pesquisas e a tentativa de implementação de políticas que visassem a melhoria da educação básica. Estas políticas encontraram dificuldades para serem implementadas, dentre as quais o documento destaca "o preparo inadequado dos professores cuja formação de modo geral, manteve predominantemente um formato tradicional, que não contempla muitas das características consideradas, na atualidade, como inerentes à atividade docente" (BRASIL, 2002 a, p.4, grifo nosso). Seguindo, apresenta diretrizes que compõem a base comum de formação docente visando a revisão criativa dos modelos em vigor até aquele período, a fim de:

- fomentar e fortalecer
processos de mudança no
interior das instituições
formadoras;
- fortalecer e aprimorar a
capacidade acadêmica e
profissional dos docentes
formadores;
-atualizar e aperfeiçoar os
formatos de preparação e
os currículos vivenciados,
considerando as


mudanças em curso na organização pedagógica e curricular da educação básica;

-dar relevo à docência como base da formação, relacionando teoria e prática;

-promover a atualização de recursos bibliográficos e tecnológicos em todas as instituições ou cursos de formação. (BRASIL, 2002a, p. 4-5)

É possível observar nestes trechos, que uma das preocupações do parecer é trazer "modernidade" ao processo de formação de professores, atribuindo ao formato tradicional o preparo inadequado ou insuficiente dos professores. Referindo-se ao período, Lígia Martins (2010) chama atenção ao recrudescimento de ideários pedagógicos alinhados às demandas de reestruturação do capital, através de suas vertentes na educação, expressas nas pedagogias do aprender a aprender, na individualização da aprendizagem, na pedagogia das competências, dentre outras que reforçam a crítica à educação tradicional.

Saviani (2000), a partir da perspectiva histórico-crítica reforça que a educação brasileira neste período, assim como nas décadas anteriores, continua sendo orquestrada por organismos internacionais (como Unesco e Banco Mundial), cujos objetivos são qualidade, produtividade e equidade com a maior racionalização possível dos recursos existentes. Sob estes pontos de vista, e considerando a atribuição dada em parte "ao preparo inadequado dos professores" para a dificuldade de implantação das políticas públicas, o que se percebe é uma tentativa clara de encontrar culpados para os problemas da educação, desde que não seja o próprio Estado, e ao mesmo tempo, apontar soluções que não estão atreladas a maiores investimentos na educação, e sim, na melhor atuação do profissional docente.

Com base no parecer CNE/CP 9/2001 e na LDB, é promulgada em 18 de fevereiro de 2002 a Resolução CNE/CP 1 (BRASIL, 2002b), que institui Diretrizes Curriculares Nacionais para a Formação de Professores da Educação Básica, em nível superior, curso de licenciatura, de graduação plena. Este documento consta de uma série de princípios, fundamentos e procedimentos que devem ser observados por cada estabelecimento de ensino em sua organização institucional e curricular. Estas diretrizes, representam avanços referentes às concepções de formação docente, na medida em que determinam que as escolas de formação garantirão com qualidade e quantidade, os recurso pedagógicos; preveem a formação de formadores incluindo estudos e investigações sobre as questões referentes ao aprendizado dos professores em formação; adotarão iniciativas que garantam parcerias para a promoção de atividades culturais destinadas aos formadores e futuros professores, além de determinar no Art. 6으, parágrafo 3으, que:

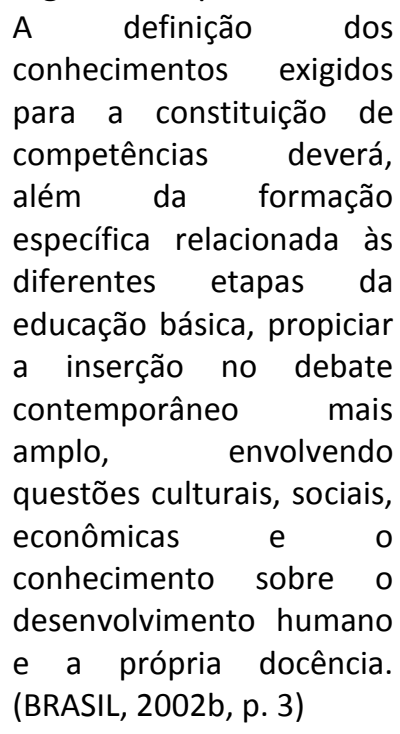

O fato de incluir nas diretrizes a intenção de propiciar a inserção no debate contemporâneo mais amplo corresponde a um avanço no sentido em que além dos conhecimentos pedagógicos, conhecimentos sobre as diferentes modalidades da educação, conteúdos das áreas de conhecimentos, da cultura geral e profissional, deve-se abrir espaço para a reflexão das dimensões sociais e políticas do ato de ensinar vinculado ao contexto sóciohistórico em que se vive.

Estas mesmas diretrizes, no entanto, determinam, em seu Art. 10 que "A seleção e o ordenamento dos conteúdos dos diferentes âmbitos de conhecimento que comporão a matriz curricular para a formação de professores, de que trata esta Resolução, serão de competência da instituição de ensino" (BRASIL, 2002b). Este é um ponto que merece destaque e que foi criticado por muitos pesquisadores da área, pois abre margem para que a formação de professores ocorra sem uma unidade curricular, o que pode provocar fragmentação nos conhecimentos 
necessários à docência, ou a insuficiência destes. Bernadete Gatti, a respeito dessas diretrizes, afirma:

\begin{abstract}
O que se verifica é que a formação de professores para a educação básica é feita, em todos os tipos de licenciatura, de modo fragmentado entre as áreas disciplinares e níveis de ensino, não contando o Brasil, nas instituições de ensino superior, com uma faculdade ou instituto próprio, formador desses profissionais, com uma base comum formativa, como observado em outros países, onde há centros de formação de professores englobando todas as especialidades, com estudos, pesquisas e extensão relativos à atividade didática e às reflexões e teorias a ela associadas. (GATTI, 2010, p. 1358)
\end{abstract}

Somando-se a essa fragmentação, temos presenciado ao que se pode chamar de "aligeiramento" da formação docente, que, diverge do que está disposto na Resolução № 2 de 2015, no Art. 9, parágrafo 30 (BRASIL, 2015, p. 9) "A formação inicial de profissionais do magistério será ofertada, preferencialmente, de forma presencial, com elevado padrão acadêmico, científico, tecnológico e cultural". De acordo com Oliveira e Maués (2012), a matrícula nos cursos de formação de professores na modalidade EaD tem superado consideravelmente as matrículas na modalidade presencial e a crítica que se faz não é referente ao uso das tecnologias educacionais adotadas nestes cursos e sim, à contradição de se formar professores longe de seu espaço de atuação, a sala de aula. Além disso, a carga horária de tais cursos, na prática, é muito menor, impedindo que a formação tenha o elevado padrão acadêmico citado na resolução acima. Martins (2010) acrescenta:

Ao levarmos em conta a argumentação segundo a qual a formação inicial via EaD deva ocorrer apenas em caráter "excepcional", bem como para as situações nas quais "não existam cursos presenciais", somos levados, também, a uma contra argumentação: tais condições não são naturais, não existem por acaso, mas atendem a uma ordem de fatores econômicos e sociais e a claros interesses de classe, no que se inclui o vasto filão de mercado que se abre para os empresários da educação. (MARTINS, 2010, p. 29-30)

Seguindo o viés de interesses de classes citado pela autora, nos deparamos com um dado que reforça essa informação: é crescente o número de instituições de ensino superior privadas que ofertam cursos de licenciatura, boa parte deles na modalidade EaD (OLIVEIRA; MAUÉS, 2012). Este é um reflexo das parcerias público-privadas que, como alternativa de reestruturação das crises do capital, abordada por Mészáros (2011), tem se tornado o meio mais utilizado para ofertar cursos de formação docente, em parceria com o Estado através de contrato de prestação de serviços ou de financiamento estudantil. Cabe salientar, que quando assumiu a presidência da república em 2003, o presidente Luís Inácio Lula da Silva, diante das mobilizações da classe docente, e numa tentativa de diminuir os altos índices de professores sem formação mínima exigida, índices estes já confrontados pelos mecanismos internacionais, lançou mão de vários programas e estratégias, dentre as quais a construção de novas universidades e institutos federais e abertura de novos cursos de licenciatura nas universidades já existentes, mas diante da impossibilidade de atender à demanda, fez parceria também com várias instituições privadas, que fornecem a modalidade EaD.

Em 2005, no art. 1ㅇ do Decreto no 5.622/05 (BRASIL, 2005), que regulamenta a educação à distância como modalidade educativa, fica prevista a obrigatoriedade de momentos presenciais para: "I - avaliações de estudantes; II - estágios obrigatórios, quando previstos na legislação pertinente; III - defesa de trabalhos de conclusão de curso, quando previstos na legislação pertinente; e IV atividades relacionadas a laboratórios de ensino, 
quando for o caso". Este decreto, no entanto, embora visasse garantir um mínimo de qualidade nos cursos em questão, não tinha como garantila, dada sua proliferação. Gatti e Barreto (2009, p. 51) sobre esta situação afirmam:

Mesmo com os cuidados legais previstos, o volume de cursos à distância para formação de professores em diferentes áreas cresceu rapidamente, sendo oferecidos em inúmeros polos mantidos pelas instituições credenciadas. Este crescimento sinaliza a necessidade de se aprimorar alguns dos processos avaliativos relativos a essas iniciativas.

Percebemos que uma alternativa para garantir os objetivos da aprendizagem era a realização de processos avaliativos. Porém, dadas as proporções da quantidade de cursos e instituições, tal iniciativa ficou na proposição. $O$ resultado, em parte, foi o que citamos anteriormente, um aligeiramento da formação sem a qualidade esperada.

Uma política que merece destaque é a criação do Programa Institucional de Bolsas de Iniciação à Docência (PIBID), em 2007, que visa o aperfeiçoamento e a valorização da formação de professores, tendo como principais objetivos "promover a articulação integrada da educação superior do sistema federal com a educação básica do sistema público, em proveito de uma sólida formação docente inicial" e "elevar a qualidade das ações acadêmicas voltadas à formação inicial de professores nos cursos de licenciaturas" (BRASIL, 2007).

Além do PIBID, outro programa que trouxe um resultado muito positivo foi o Plano Nacional de Formação de Professores da Educação Básica (Parfor), criado em 2009, através do decreto № 6.755, de 29 de janeiro de 2009 (BRASIL, 2009), que abriu vagas em universidades públicas em cursos de licenciatura e segunda licenciatura, na modalidade presencial, exclusivas para professores da rede pública da educação básica que ainda não eram licenciados ou não eram licenciados na área em que atuavam. Estes programas, dentre outros, integram um conjunto de políticas públicas do governo federal em parceria com estados, municípios e instituições de ensino superior com o objetivo de transformar o magistério.

No contexto da legislação, é importante destacarmos também que a Política Nacional de Formação Docente instituída pelo decreto № 6.755 de 2009, foi substituído mais tarde pelo decreto № 8.752, de 9 de maio de 2016 para atender ao que está disposto no Plano Nacional de Educação de 2014. Esta política tem como princípios, dentre outros:

I - o compromisso com um projeto social, político e ético que contribua para a consolidação de uma nação soberana, democrática, justa, inclusiva e que promova a emancipação dos indivíduos e dos grupos sociais;

[...]

IX - a valorização dos profissionais da educação, traduzida em políticas permanentes de estímulo à profissionalização, à progressão na carreira, à melhoria das condições de remuneração e à garantia de condições dignas de trabalho;

XII - os projetos pedagógicos das instituições formadoras que reflitam a especificidade da formação dos profissionais da educação básica, que assegurem a organicidade ao trabalho das diferentes unidades que concorram para essa formação e a sólida base teórica e interdisciplinar e que efetivem a integração entre teoria e as práticas profissionais; (BRASIL, 2016a)

A análise destes princípios, em particular, nos permite perceber o avanço em relação à concepção de educação como promotora da emancipação humana e o reconhecimento da necessidade de valorização dos profissionais da educação atreladas a projetos de formação que contemplem a diversidade de saberes e se 
baseiem numa base teórica ampla, pedagógica e específica da área do saber em que atuam.

Outro ponto que merece destaque, se refere à organização desta política, que contará com um Comitê Gestor Nacional e com Fóruns Estaduais permanentes de apoio à Formação dos Profissionais da educação Básica, ambos deverão ter representantes dos profissionais da educação, bem como de entidades científicas, e poderão sugerir ajustes nos planos estratégicos para formação, nas ações e programas que dão sustentação à política. Esta medida tende a garantir que as decisões acerca da formação dos professores não serão tomadas de forma verticalizada e que haja uma participação da classe na determinação dos rumos a serem tomados nos programas de formação.

Um exemplo de que esta mobilização dos profissionais da educação dará certo pode ser percebido no Plano Nacional de Educação (PNE) que foi elaborado com ampla participação social e resultou numa lei que envolve todas as modalidades e dimensões da educação básica e superior, perpassando pela valorização docente, em todos os seus aspectos.

Sobre a formação docente, o PNE determina:

Meta 15 - garantir, em regime de colaboração entre a União, os Estados, o Distrito Federal e os Municípios, no prazo de um ano de vigência deste PNE, política nacional de formação dos profissionais da educação de que tratam os incisos I, II e III do caput do art. 61 da Lei no 9.394, de 20 de dezembro de 1996, assegurado que todos os professores e as professoras da educação básica possuam formação específica de nível superior, obtida em curso de licenciatura na área de conhecimento em que atuam; [...]

Meta 16 - formar, em nível de pós-graduação, cinquenta por cento dos professores da educação básica, até o último ano de vigência deste PNE, e garantir a todos(as) os(as) profissionais da educação básica formação continuada em sua área de atuação, considerando as necessidades, demandas e contextualizações dos sistemas de ensino. (BRASIL, 2014, p.78-80)

A partir dessa Lei, tanto a formação inicial como a continuada passam a ter um espaço de destaque em meio às políticas educacionais, sendo reconhecidas como critério indispensável para a valorização e desenvolvimento profissional docente, e também como requisito básico para a melhoria da qualidade da educação.

Durante o período que se estende do início dos anos 2000 até 2016, muitas foram as conquistas para o profissional docente no que se refere à legislação. Mesmo com os problemas que permaneceram, é inegável que muitos foram solucionados e outros diminuíram consideravelmente. É importante destacar que durante os governos Lula e Dilma os investimentos em educação, inclusive na formação docente, aumentaram de forma gradativa. Uma prova disso são os dados que foram divulgados pelo Inep (BRASIL, 2018), que mostram que a quantidade de professores com nível superior saltou de 68,4\%, em 2007 para 78,3\% em 2017 (conforme gráfico a seguir), cerca de $10 \%$ a mais que representam em torno de 430 mil novos professores com este nível de formação. 
Porcentagem de professores da educação básica com nível

superior

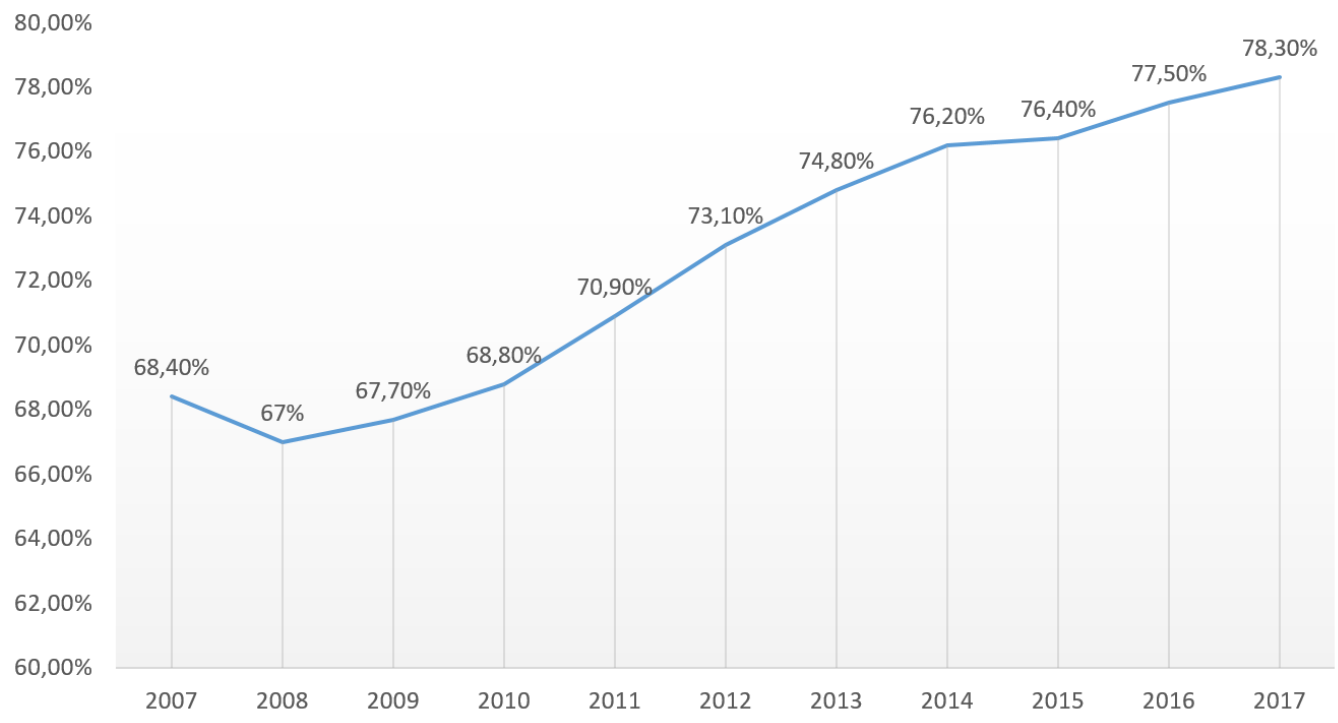

Fonte: INEP (BRASIL, 2018)

Sendo que a meta é atingir 100\% dos docentes com formação até 2024 e considerando o cenário político de nosso país e as investidas neoliberais cada vez mais presentes, talvez essa meta não se efetive. Com base nesta constatação, faremos uma reflexão maior a respeito das influências neoliberais e suas consequências nas políticas de formação docente.

\section{INDÍCIOS DA INFLUÊNCIA NEOLIBERAL NAS POLÍTICAS E NA REALIDADE DA FORMAÇÃO DOCENTE}

Um documento de 2014 divulgado pelo Banco Mundial (BM) com o título "Professores Excelentes: Como melhorar a aprendizagem dos estudantes na América Latina e no Caribe" (BRUNS; LUQUE. 2014) traz uma demonstração de como o sistema do capital vê a educação e o papel dos professores na sociedade contemporânea, fornecendo "orientações", inclusive, sobre como deve ser a formação destes profissionais.

No prefácio deste documento que apresenta claramente uma ideia da escola como empresa que deve ser gerida com foco na produtividade e eficácia dos seus funcionários, os autores destacam as políticas progressivas de assistência social desenvolvidas a partir dos anos 2000 que conseguiram tirar mais de 80 milhões de pessoas da pobreza e tornou o ensino fundamental quase universal.

Seguindo, os autores informam que "a desaceleração econômica dos últimos anos lançou dúvidas sobre a sustentabilidade do progresso da década anterior" (BRUNS; LUQUE, 2014, p. 12), vinculada a fatores externos como o crescimento mais lento da China e o aumento dos juros internacionais. A solução sugerida pelos mesmos para este problema, porém, não pode ser esperada do exterior, e a região em questão, incluindo o Brasil, "precisa desenvolver as próprias estratégias de produção mais diversificada, exportações de maior valor e crescimento sustentável de longo prazo" (BRUNS; LUQUE, 2014, p. 12). Para que tais ações sejam possíveis afirmam ser necessário aumentar o capital humano, pois "é a aprendizagem dos estudantes [...] que produz a maior parte dos benefícios econômicos dos investimentos na educação" (BRUNS; LUQUE, 2014, p. 12). Mais à frente, argumentam que "a qualidade da educação está condicionada à qualidade de nossos professores" (BRUNS; LUQUE, 2014, p. 12).

Cabe destacar que, dentre os autores do referido documento, a maioria é economista e consultores do Banco Mundial, fato que merece atenção dada a intenção do documento, que segundo eles, é propor melhorias para a educação nos países da América Latina e do Caribe. Freitas (2014) faz uma crítica à interferências de profissionais como estes, chamados por Ravitch (2011) de reformadores educacionais (corporate reformers), que, não sendo profissionais da educação, em sua maioria, tentam imprimir nas escolas a lógica empresarial e obter daí lucros e resultados considerados mais 
produtivos. Para tanto, tratam a sala de aula e a própria escola como uma linha de produção e the impõem medidas que informam se a produção está sendo feita segundo as metas estabelecidas, isso sem levar em conta a multiplicidade de fatores que interferem no processo de ensinoaprendizagem e que são diversos de uma instituição para outra e até mesmo dentro da uma pequena escola.

Algumas das informações do documento Professores Excelentes merecem destaque, a saber: 1- "evidências globais e regionais sobre a importância dos resultados da educação para o crescimento econômico e a competitividade" (BRUNS; LUQUE. 2014 p. 25); 2- "A baixa qualidade média dos professores latinoamericanos e caribenhos é o fator limitante sobre o progresso da educação na região" (BRUNS; LUQUE. 2014 p. 25); 3- "A qualidade dos professores na região é comprometida por um fraco domínio do conteúdo acadêmico, bem como por práticas ineficazes em sala de aula[...]; fazem uso limitado dos materiais didáticos disponíveis, especialmente da tecnologia da informação e comunicação (TIC) e não conseguem manter os estudantes interessados. (BRUNS; LUQUE, 2014, p. 25); 4- O maior desafio para elevar a qualidade dos professores não é fiscal nem técnico, mas político, porque os sindicatos dos professores em todos os países da América Latina são grandes e politicamente ativos (BRUNS; LUQUE. 2014, p. 26);

Ao analisarmos o item 1, percebemos que a intenção do documento não é mostrar os resultados da educação com vistas à formação humana e voltada para o desenvolvimento social, histórico e crítico dos sujeitos. O objetivo é unicamente o crescimento econômico e a competitividade. Esta é uma evidência de como a educação tem sido utilizada para atender aos fins do sistema do capital, que a cada nova crise estrutural, como afirma Mészáros (2011), se reestrutura e utiliza novos meios para atingir seus fins. Nesta perspectiva, formar mão de obra para atender às demandas da produção e do mercado passa a ser o principal objetivo da educação escolar, sem que este seja, muitas vezes, percebido pelos sujeitos envolvidos. Além disso, as próprias relações sociais que acontecem no interior da sociedade capitalista tratam de desenvolver uma aceitação das condições impostas pelo sistema vigente, determinando novas formas de ensino e aprendizagem que convergem para atender às novas necessidades de reprodução desta mesma sociedade.

Partem desta constatação, as mudanças que tem acontecido no sistema educativo, tais como a incorporação de avaliações externas e internacionais, a atuação dos reformadores educacionais propondo inovações que visem à maior produtividade, a inserção do setor privado na educação através de parcerias que, às vezes com a desculpa de "não terem fins lucrativos", promovem mudanças educativas e impõem materiais didáticos que apenas reforçam a manutenção da sociedade, além de determinar quem são os culpados pelos baixos resultados encontrados nas avaliações citadas. Em nosso país, há um grupo expressivo de reformadores que também tem desenvolvido esta mesma ideologia, como afirmam Beltrão e Taffarel:

No Brasil, formam-se
organizações com função
análoga a exercida por
sujeitos coletivos no que
se refere à indução,
planejamento e execução
de políticas educacionais,
organizando redes locais
que se integram à rede
internacional.
organizaçãor
conquistou
evidência foi a Todos Pela
Educação (TPE), criada e
mantida, principalmente,
por empresas dos setores
financeiro e industrial.
(BELTRÃO;
2017, p. 5).

O movimento Todos Pela Educação, criado em 2005, utilizou a mesma justificativa de baixa qualidade da educação e a pequena capacidade competitiva do país, para lançar o projeto Compromisso Todos pela Educação em parceria com o Estado e demais esferas públicas de poder, atingindo uma posição estratégica e hegemônica no campo educacional.

Em relação aos itens 2 e 3, observamos que o Banco Mundial, através do documento Professores Excelentes, afirma que o fator limitante para o progresso da educação é o baixo nível dos professores. Tal afirmação é muito tendenciosa, pois visa unicamente estabelecer um novo padrão de formação que seja eficaz e produtivo para o interesse que Ihe apraz. Um professor, que atenda a estas expectativas, 
considerado por eles como "bem treinado" é aquele que consegue adquirir a capacidade de assegurar que seus alunos aprendam, independente dos fatores sociais em que vivem, das privações, da falta de apoio educativo na família, da falta de acesso a livros e outros materiais, bem como de suas próprias condições bio-psico-afetivas. Deixam também de colocar em pauta a realidade das salas de aulas, que normalmente é marcada por um alto número de alunos com características e níveis de aprendizagem diferentes, sem contar as condições de trabalho do professor. A proposta de formação de professores do documento se insere na afirmação:

São desafios importantes para os programas de formação de professores na América Latina e no Caribe, tanto anteriores ao serviço quanto em serviço: garantir que os professores reconheçam a importância de atrair todos os alunos para o processo de aprendizagem, estejam equipados com uma série de estratégias de ensino para conseguir isso e que cheguem à escola todos os dias preparados para usar essas estratégias, e cada minuto do tempo de aula, com eficiência. (BRUNS; LUQUE, 2014, p. 40)

Estas informações tem tido grandes influências no estabelecimento das políticas públicas nacionais, que devido a concepções como a dos reformadores do Banco Mundial e sua influência, trazem uma série de novos desafios à atuação dos professores, bem como à sua formação. Como já foi afirmado, muitas conquistas foram atingidas pelos professores nas últimas décadas no tocante ao direito à formação inicial em nível superior resguardados pela lei, refletindo diretamente na quantidade de docentes com nível superior, que aumentou consideravelmente.

No entanto, como a lógica do capital é incontrolável e possui um caráter sociometabólico, ele encontra meios para superar "as resistências que encontra e adquire um 'poder soberano' para dominar todas as facetas do processo de reprodução societária"
(MÉSZÁROS, 2011, p.711). Isso é evidenciado pelas próprias leis e resoluções que resguardam os direitos mas estão também com marcas da interferência do setor privado e da lógica neoliberal capitalista. O PNE, por exemplo, que é considerado um marco das políticas públicas, traz a determinação de que os objetivos da aprendizagem devem seguir à base nacional comum curricular (BNCC), que foi aprovada na sua terceira versão e, diferente do PNE, foi formulada sem participação efetiva dos professores, demais profissionais da educação e da sociedade. Sobre a formação dos professores e a BNCC, o PNE determina em sua estratégia 15.6:

Promover a reforma
curricular dos cursos de
licenciatura e estimular a
renovação pedagógica, de
forma a assegurar o foco
no aprendizado do(a)
aluno(a), dividindo a carga
horária em formação
geral, formação na área do
saber e didática específica
e incorporando as
modernas tecnologias de
informação
comunicação, e
articulação com a base
nacional comum dos
currículos da educação
básica, de que tratam as
estratégias 2.1, 2.2, 3.2 e
3.3 deste PNE (BRASIL,
2014, p. 78, grifo nosso)

Não haveria problema nesta meta, se a base que estava por ser construída, não representasse a maior parte dos conteúdos a serem estudados na educação básica, num país tão diverso como o nosso, e se não fossem escolhidos por empresas e reformadores educacionais que tem tentado a todo custo desenvolver nas escolas um modelo de educação voltado para a reprodução da sociedade de classes e para a preparação dos alunos para posteriormente serem aprovados nas avaliações externas e mais adiante servirem como mão de obra para o mercado de trabalho. Freitas (2014) demonstrou sua preocupação com respeito à base, afirmando que sem uma discussão e definição prévia de uma matriz formativa, corriase o risco de reforçar uma matriz conteudista que deixasse de fora importantes dimensões da formação humana. E foi isso que aconteceu com 
a nova BNCC aprovada em 2017, com a qual a formação de professores deverá, por lei, estar articulada.

A agenda neoliberal para a educação e para a formação de professores, ganhou ainda mais força a partir de 2016 com o impeachment da presidenta Dilma Rousseff e a ascensão de Michel Temer ao poder. Desde então, muitas foram as medidas e reformas que tem dificultado o processo de formação docente. Podemos citar a aprovação da PEC do Teto dos Gastos que congelou os gastos em educação e outros setores por vinte anos (BRASIL, 2016b); o veto à prioridade prevista para o PNE para 2018 através da Lei de Diretrizes Orçamentárias sancionada em 2017 (BRASIL, 2017a), ações que comprometem diretamente o cumprimento das metas de formação e valorização docente.

Outra medida que demonstra a falta de reconhecimento da importância da formação docente para o processo de ensino-aprendizagem ficou explícita no parágrafo IV, do artigo 61, da Lei 13.415/2017, que institui a Política de Fomento à Implementação de Escolas de Ensino Médio em Tempo Integral (BRASIL, 2017b). Nesta Lei, que como um todo promove de forma clara a privatização da educação, abre-se margem para que profissionais com "notório saber" possam ministrar aulas nas turmas de ensino médio, sem que tenham passado por cursos de licenciatura, bastando apenas que apresentem domínio do conteúdo que deverá ser ministrado. Esta medida resulta numa maior desvalorização da carreira docente, uma vez que qualquer pessoa pode assumir seu lugar bastando ter o notório saber. 0 Estado mais uma vez, tenta se isentar de sua responsabilidade com a formação docente e com a qualidade da educação, demonstrando que neste governo a educação não é prioridade.

É necessário mencionar também as constantes ameaças de fim e interrupção do Programa Nacional de Iniciação à Docência (PIBID) que já foi citado anteriormente. Instituído em 2007 e implantado em 2008 no governo Lula, o PIBID consolidou-se como um programa fundamental tanto para a permanência de estudantes de licenciatura nas universidades, por causa das bolsas de estudos que recebiam, e, como um importante elo entre as instituições formadoras e as escolas de educação básica de todo o Brasil. Com o pretexto de inviabilidade orçamentária e justificado pelos frequentes cortes nas verbas para a educação, o presidente Michel Temer propõe novas regras para o programa que resultaram em seu enfraquecimento. Mais uma vez percebemos as estratégias capitalistas de diminuir a participação do Estado nas políticas públicas e no fomento de uma educação de qualidade para todos, uma vez que esta perpassa por uma formação docente também de qualidade.

Diante deste quadro de tantos retrocessos, do desmonte de direitos conquistados e de demonstrações de sucateamento da educação pública e da precarização do trabalho docente, nos perguntamos se é possível uma mudança desta situação de forma que professores sejam valorizados, que seus direitos sejam garantidos, que sua formação seja efetiva e vista como momento importante de seu desenvolvimento profissional e por fim se é possível que diante dessa lógica devastadora de obtenção de lucros e acúmulo de capital, os sujeitos tenham uma educação de qualidade.

\section{A NECESSÁRIA FORMAÇÃO POLÍTICA PARA OS DOCENTES}

Mészáros (2008, p. 25), em seu livro $A$ Educação Para Além do Capital, ao tratar dos processos educacionais e sua ligação com os processos sociais mais abrangentes de reprodução, afirma que "uma reformulação significativa da educação é inconcebível sem a correspondente transformação do quadro social no qual as práticas educacionais da sociedade devem cumprir as suas vitais e historicamente importantes funções de mudança".

É seguindo este pensamento que voltamos à informação do item 4 do documento do Banco Mundial, já mencionado neste artigo, de que o maior desafio para elevar a qualidade dos professores é político, pois os sindicatos destes professores são grandes e politicamente ativos. Esta afirmação do BM só corrobora com a constatação de que a intenção do sistema do capital é a reprodução da sociedade de classes e a manutenção do sistema de exploração capitalista sobre o trabalhador.

$O$ fato de afirmarem que os sindicatos 'politicamente ativos' são um entrave à atuação docente nos moldes que eles esperam nos dá a certeza de que Mészáros tem razão e que a mudança necessária na sociedade só será possível a partir das práticas educacionais. Saviani (2008), quando defende a pedagogia histórico-crítica, demonstra concordância com este pensamento ao afirmar que a prática social 
se põe como ponto de partida e de chegada da prática educativa, sendo os professores, os principais responsáveis pela formação humana, dentro do contexto escolar, "onde professor e aluno se encontram igualmente inseridos ocupando, porém, posições distintas, condição para que travem uma relação fecunda na compreensão e encaminhamento da solução dos problemas postos pela prática social" (SAVIANI, 2008, p. 25).

Os reformadores educacionais não comungam desta ideia, o que faz com que vejam os sindicatos, que são formados por profissionais da educação que se unem contra a exploração, a precarização e a desvalorização da carreira, como empecilho para a qualidade (leia-se produtividade e eficiência) do trabalho docente. Para estes reformadores e demais representantes do capitalismo, a dimensão política e a capacidade de articulação da classe trabalhadora como forma de resistência e na construção de ações contra hegemônicas são inaceitáveis.

Lúcia Bruno (2011), relacionando a educação aos processos de mais-valia, informa que em muitos países, os capitalistas não estão interessados em compensar a baixa qualificação dos profissionais e nem apoiar o investimento na educação:

Daí a degradação do
ensino nessas regiões e a
importância atribuída à
escola e à formação de
professores serem
praticamenter nulas.
Nesses países, o Estado
tem garantido na lei, mas
não na prática, formação
básica para os
trabalhadores. Daí serem
os próprios jovens (alguns
deles) a assumirem os
custos de uma formação
mais complexa, pagando-a
por meior do
assalariamento precoce.
(BRUNO, 2011, p. 550)

Esta afirmação explica o aumento dos retrocessos e da diminuição dos investimentos em formação de professores no Brasil nos últimos anos, contrariando o PNE e demais leis que amparam os docentes e, ao mesmo tempo, servem para instiga-los a desenvolver uma atitude de defesa dos seus direitos, neste caso específico, o direito à formação básica em nível superior e à formação continuada em serviço. Devem ainda exigir que esta formação tenha sua qualidade assegurada e que não sirva apenas para atender às exigências estritas do mercado de trabalho e de reprodução da sociedade de classes na qual estamos inseridos.

Segundo Schlesener (2009, p. 107), "a dimensão política da educação se expressa no reconhecimento dos conflitos de classes que constituem a base da sociedade moderna e da necessidade de as classes trabalhadoras criarem a sua identidade e a sua cultura no processo de construção da hegemonia". Concordando com esta, citamos Florestan Fernandes que ainda na década de 80 , manifestou-se sobre o necessário amadurecimento da consciência política dos professores contra a dominação que lhes tem sido imposta.

[...] [o professor] precisa
se colocar na situação de
um cidadão de uma
sociedade capitalista
subdesenvolvida e com
problemas especiais e,
nesse quadro, reconhecer
que tem um amplo
conjunto de
potencialidades, que só
poderão ser dinamizadas
se ele agir politicamente,
se conjugar uma prática
pedagógica eficiente e
uma ação política da
mesma qualidade.
(FERNANDES, 1986, p. 31)

Este amadurecimento é necessário por que à medida que os professores forem desenvolvendo sua consciência política, esta mesma consciência norteará tanto suas atividades em classe, contribuindo para uma formação sólida dos educandos, tanto no sentido acadêmico, como no social, crítico e histórico, como também garantirá que tenham meios para permanecerem na luta pela efetivação de seus direitos e pela conquista de novos. Há que se considerar ainda, segundo Moreira Neto (1998) que não se pode fazer educação e magistério sem uma base política de conhecimento, o que reforça a necessidade de desenvolver esta capacidade.

De acordo com Barros,

Quando professores forem mais valorizados e melhorarem seu nível de 


\begin{abstract}
escolarização (pósgraduação)

remuneração, unirem-se como classe organizada e transformadora, haverá maior difusão da "ação pedagógica humanizadora e transformadora do sistema de ensino". (BARROS, 2005, p. 187, grifos do autor)
\end{abstract}

A formação política dos professores é, portanto, um requisito muito importante para sua prática, inclusive por que como a educação tem sido reformulada para atender às demandas e mudanças do capitalismo. Até os cursos de formação de professores tendem a ser reformulados para tentar preparar os professores para atender a este fim.

É nesse contexto que Márcia Martins propõe:

[...] urge a proposição de um modelo de formação alternativo, no qual a construção de conhecimentos se coloque a serviço do desvelamento da prática social, apto a promover questionamento da realidade fetichizada e alienada que se impõe aos indivíduos. Que supere em definitivo, os princípios que na atualidade têm norteado a formação escolar, em especial a formação de professores. (MARTINS, 2010, p. 20)

Desse modo, desenvolver a consciência política deve ser algo inerente à formação e atuação docente, por que só assim teremos a chance de entender os mecanismos de exploração e nos posicionar contra eles, tendo uma maior chance de alcançar êxito se mantivermos uma resistência ativa e coletiva, o que, segundo Saviani, abrirá possibilidades de "conduzir o embate com alguma chance de reverter a situação, senão imediatamente, acumulando energia para o momento em que a correlação de forças se tornar mais favorável" (SAVIANI, 2003, p. 237). Talvez, a correlação de forças ainda não nos seja favorável, pelo fato de que muitos docentes ainda não estão convencidos da capacidade de transformação que a ação coletiva de uma classe tem e ainda não buscaram envolver-se com seu pares nas causas de sua classe.

\section{ALGUMAS CONSIDERAÇÕES}

Embora os avanços educacionais já conquistados pelas leis e diretrizes ao longo de anos, no que se refere à formação docente, estejam ameaçados pelas novas políticas educacionais implementadas no Brasil sob a influência dos reformadores neoliberais, uma vez que esta disfarça o profundo esmaecimento da construção do conhecimento sólido para a formação docente e valoriza a eficiência, a produtividade e o desenvolvimento de uma formação voltada para o preparo dos educandos para o mercado de trabalho, não podemos perder de vista que os próprios professores são os responsáveis pela tomada de atitude e mudança de rumos que a educação precisa tomar.

Sabemos que a realidade que vivemos hoje é o resultado de uma construção histórica que precisa ser conhecida e enfrentada, já que o que tem predominado nas últimas décadas é o fortalecimento do ideal burguês de sociedade e de educação. Da mesma forma que o capitalismo possui a capacidade sociometabólica de se reestruturar a cada nova crise que enfrenta, cabe aos docentes fortalecerem-se como profissionais da educação, tanto de modo individual no cotidiano do trabalho docente, como de modo coletivo por meio dos sindicatos e demais instituições de luta coletiva, para que a cada nova investida contra a garantia de seus direitos, eles consigam desenvolver mecanismos para enfrentar as novas proposições deste sistema. Antes disso, é necessário que busquem conhecer na totalidade os ideais capitalistas neoliberais, pois só assim desenvolverão a consciência de contra quem e contra o que devem lutar.

\section{REFERÊNCIAS:}

BARROS, Silvino Morais. A formação política do professor e uma introdução à teoria da reprodução cultural no ensino formal. Revista Solta a Voz, v. 16, n. 2 p. 179-189, 2005. DOI: 10.5216/rp.v16i2.6877. Disponível em: https://www.revistas.ufg.br/sv/article/view/6877 Acesso em: 13 jul. 2018.

BELTRÃO, José Arlen; TAFFAREL, Celí. A ofensiva dos reformadores empresariais $-E$ a resistência 
de quem defende a educação pública. Revista

Retratos da Escola, Brasília, v. 11, n. 21, p. 587601, jul./dez. 2017. Disponível em: $<$ http//www.esforce.org.br> Acesso em: 24 jul. 2018.

BRASIL. Parecer CNE/CP 9/2001 - Diretrizes Curriculares Nacionais para a Formação de Professores da Educação Básica, em nível superior, curso de licenciatura, de graduação plena -HOMOLOGADO Despacho do Ministro em 17/1/2002 a, publicado no Diário Oficial da União de 18/1/2002, Seção 1, p. 31. Disponível em: http://portal.mec.gov.br/cne/arquivos/pdf/009.p df Acesso em: 23 jul. 2018.

BRASIL. Ministério da Educação. Conselho Nacional de Educação. Conselho Pleno. Resolução CNE/CP1, de 18 de fevereiro de 2002 b. Institui diretrizes curriculares nacionais para a formação de professores da educação básica, em nível superior, curso de licenciatura, de graduação plena. Diário Oficial da União, Brasília, 9 de abril de 2002. Seção 1, p. 31.

BRASIL. Decreto no 5.622, de 19 de dezembro de 2005. Regulamenta o art. 80 da Lei № 9.394, de 20 de dezembro de 1996, que estabelece as diretrizes e bases da educação nacional. Diário Oficial da União, Brasília, 19 de dezembro de 2005. Disponível em: http://www.planalto.gov.br/ccivil_03/_ato20042006/2005/decreto/d5622.htm Acesso em: 22 jul. 2018.

BRASIL. Portaria Normativa № 38, de 12 de dezembro de 2007. Dispõe sobre o Programa de Bolsa Institucional de Iniciação à Docência - PIBID. nacional. Diário Oficial da União Brasília, DF, de 13 de dezembro de 2007. Disponível em: https://www.capes.gov.br/images/stories/downl oad/legislacao/Portaria_Normativa_38_PIBID.pdf Acesso em: 22 jul. 2018.

BRASIL. Decreto no 6.755, de 29 de janeiro de 2009. Institui a Política Nacional de Formação de Profissionais do Magistério da Educação Básica, disciplina a atuação da Coordenação de Aperfeiçoamento de Pessoal de Nível Superior CAPES no fomento a programas de formação inicial e continuada, e dá outras providências. Diário Oficial da União Brasília. Brasília, DF, de 29 de janeiro de 2009. Disponivel em: https://www.capes.gov.br/images/stories/downl
oad/legislacao/Decreto-6755-2009.pdf acesso em: 25 jul. 2018.

BRASIL. Resolução no 2, de 1어 de julho de 2015 Define as Diretrizes Curriculares Nacionais para a formação inicial em nível superior (cursos de licenciatura, cursos de formação pedagógica para graduados e cursos de segunda licenciatura) e para a formação continuada. Diário Oficial da União Brasília. Brasília, DF, 1ำ de julho de 2015. Disponível em:

http://portal.mec.gov.br/index.php?option=com _docman\&view=download\&alias=70431-res-cnecp-002-03072015-pdf\&category_slug=agosto2017-pdf\&ltemid=30192 Acesso em: 23 jul. 2018.

BRASIL. Lei n.o 13.005, de 25 de junho de 2014. Aprova o Plano Nacional de Educação - PNE e dá outras providências. Diário Oficial da União Brasília. Brasília, DF, de 26 de junho 2014 - Edição extra.

BRASIL. Decreto no 8.752, de 9 de maio de 2016 a. Dispõe sobre a Política Nacional de Formação dos Profissionais da Educação Básica. Diário Oficial da União Brasília. Brasília, DF, de 9 de maio de 2016. Disponível em:http://www.planalto.gov.br/ccivil_03/_ato20 15-2018/2016/decreto/d8752.htm Acesso em: $19 / 07 / 2018$

\section{BRASIL. Emenda Constitucional no 95 de}

15/12/2016. Altera o ato das disposições constitucionais transitórias, para instituir o novo regime fiscal, e dá outras providências. Brasília, 2016b. Disponível em:

<http://legis.senado.leg.br/legislacao/ListaTextoS igen .action ?norma $=540698 \& i d=14374770 \&$ idBin ario $=15655553 \&$ mime $=$ application $/$ rtf.n $>$ Acesso em: 03 maio 2018.

BRASIL. Lei no 13.473, de 08 de agosto de 2017 a. Dispõe sobre as Diretrizes para a elaboração e execução da Lei Orçamentária de 2018 e dá outras providências. Brasília, 2017. Disponível em:

$<$ http://www.planalto.gov.br/ccivil 03/ ato20152018/2017/Lei/L13473.htm> Acesso em: 03 maio 2018.

BRASIL. Lei no 13.415, de 16 de fevereiro de 2017 Altera as Leis nos 9.394, de 20 de dezembro de 1996, que estabelece as diretrizes e bases da educação nacional, e 11.494, de 20 de junho 
2007, que regulamenta o Fundo de Manutenção e Desenvolvimento da Educação Básica e de Valorização dos Profissionais da Educação, a Consolidação das Leis do Trabalho - CLT, aprovada pelo Decreto-Lei no 5.452, de 10 de maio de 1943, e o Decreto-Lei no 236, de 28 de fevereiro de 1967; revoga a Lei no11.161, de 5 de agosto de 2005; e institui a Política de Fomento à Implementação de Escolas de Ensino Médio em Tempo Integral. Brasília, 2017b. Disponível em: http://www.planalto.gov.br/ccivil_03/_Ato20152018/2017/Lei/L13415.htm Acesso em: 24 jul. 2018.

BRASIL. Instituto Nacional de Estudos e Pesquisas Educacionais Anísio Teixeira. Relatório do 20 Ciclo de Monitoramento das Metas do Plano Nacional de Educação - 2018. - Brasília, DF : Inep, 2018.

BRUNO, Lúcia. Educação e Desenvolvimento Econômico no Brasil. Revista Brasileira de Educação, v. 16, n. 48, set.-dez. 2011.

BRUNS, Barbara; LUQUE, Javier. Great Teachers: How to Raise Teacher Quality and Student Learning in Latin America and the Caribbean. Overview booklet. Washington, D.C.: Banco Mundial, 2014.

FERNANDES. Florestan. A formação política e o trabalho do professor. In.: CATANI, Denice Bárbara et al. (Orgs.). Universidade, escola e formação de professores. São Paulo: Brasiliense, 1986.

FERREIRA JUNIOR, Amarílio. A influência marxista no PPGE/UFSCar (1976-1991). Revista Eletrônica de Educação, v.11, n.1, p.86-96, jan./maio, 2017 DOI: 10.14244/198271992180, Disponível em: http://www.reveduc.ufscar.br/index.php/revedu c/article/view/2180/567. Acesso em: 15/ 07/ 2018.

FREITAS. Luiz Carlos de. Os reformadores empresariais da educação e a disputa pelo controle do processo pedagógico na escola. Educação e Sociedade, Campinas, v.35, nº 129, p. 1085-1114, out.-dez., 2014. DOI: 10.1590/ES0101-73302014143817, Disponível em:

http://www.scielo.br/scielo.php?script=sci_arttex t\&pid=S0101- 73302014000401085\&lng=pt\&tlng=pt. Acesso em: 15/ 07/ 2018.

GATTI, Bernadete Angelina; Barreto, Elba Siqueira de Sá. Professores do Brasil: impasses e desafios. Brasília: UNESCO, 2009. Disponível em: http://unesdoc.unesco.org/images/0018/001846 /184682por.pdf. Acesso: 19 jul. 2018.

GATTI, B. A. Formação de professores no Brasil: Características e problemas. Educ. Soc., Campinas, v. 31, n. 113, p. 1355-1379, out.-dez. 2010. Disponível em: http://www.scielo.br/pdf/es/v31n113/16.pdf Acesso em: 14 jul. 2018.

GIL, Antônio Carlos. Como elaborar projetos de pesquisa. 4. ed. São Paulo: Atlas, 2002.

LAKATOS, E. M.; MARCONI, M. A. Fundamentos da metodologia científica. 5. ed. São Paulo: Atlas, 2003.

LOMBARDI, José Claudinei. Reflexões sobre educação e ensino na obra de Marx e Engels Campinas, SP: [s.n.], 2010.

MARTINS, Lígia Márcia. O legado do século XX para a formação de professores. IN: MARTINS, L. M., and DUARTE, N., orgs. Formação de professores: limites contemporâneos e alternativas necessárias [online]. São Paulo: Editora UNESP; São Paulo: Cultura Acadêmica, 2010. Disponível em: <http://books.scielo.org>. Acesso em: 15/ 07/ 2018.

MÉSZÁROS, István. A educação para além do capital. Tradução Isa Tavares. 2. ed. São Paulo: Boitempo, 2008.

MÉSZÁROS, István. Para além do capital: rumo a uma teoria da transição. Tradução Paulo Cezar Castanheira, Sérgio Lessa. São Paulo: Boitempo, 2011.

MOREIRA NETO, Diogo de Figueiredo. Curso de Direito Administrativo. Rio de Janeiro: Forense, 1998.

OLIVEIRA, João Ferreira; MAUÉS, Olgaíses Cabral. A formação docente no Brasil: cenários de mudança, políticas e processos em debate. In: OLIVEIRA, Dalila Andrade; VIEIRA, Lívia Fraga. Trabalho na educação básica: a condição 
docente em sete estados brasileiros. Belo

Horizonte: Fino Traço, 2012.

RAVITCH, Diane. National opportunity to learn summit. 2011. Disponível em:

<https://www.wested.org/

online_pubs/board/diane-ravitch-speech.pdf >.

Acesso em: 01 dez. 2016.

SAVIANI, Dermeval. Sobre a natureza e

especificidade da educação: Em Aberto.22. ed..

Brasília: MEC/INEP, 1984.

SAVIANI, Dermeval. Pedagogia Histórico-Crítica: primeiras aproximações. 7. ed. Campinas, SP:

Autores Associados, 2000.

SAVIANI, Dermeval. A nova lei da educação:

trajetória, limites e perspectivas. 8. ed.

Campinas/SP: Autores Associados, 2003.

SAVIANI, Dermeval. Teorias pedagógicas contrahegemônicas no Brasil. Revista do Centro de Educação e Letras da Unioeste, Campus de Foz do Iguaçu, v.10, $n^{\circ} 2$, p. 11-28, 2008.

SCHLESENER, Anita Helena. A Escola de Leonardo: política e educação nos escritos de Gramsci. Brasília: Liber Livro, 2009.

Submetido em: 03/09/2018

Correções Obrigatórias: 24/11/2018

Aceite Final em: 01/12/2018 